University of Nebraska - Lincoln

DigitalCommons@University of Nebraska - Lincoln

Faculty Papers and Publications in Animal

Science

Animal Science Department

2020

\title{
Lamb wool shedding is a good predictor of ewe wool shedding
}

\author{
Napoleón Vargas Jurado \\ University of Nebraska - Lincoln \\ Larry Kuehn \\ USMARC, Larry.Kuehn@ars.usda.gov \\ Ronald M. Lewis \\ University of Nebraska - Lincoln, ron.lewis@unl.edu
}

Follow this and additional works at: https://digitalcommons.unl.edu/animalscifacpub

Part of the Genetics and Genomics Commons, and the Meat Science Commons

Vargas Jurado, Napoleón; Kuehn, Larry; and Lewis, Ronald M., "Lamb wool shedding is a good predictor of ewe wool shedding" (2020). Faculty Papers and Publications in Animal Science. 1081.

https://digitalcommons.unl.edu/animalscifacpub/1081

This Article is brought to you for free and open access by the Animal Science Department at DigitalCommons@University of Nebraska - Lincoln. It has been accepted for inclusion in Faculty Papers and Publications in Animal Science by an authorized administrator of DigitalCommons@University of Nebraska Lincoln. 


\title{
Lamb wool shedding is a good predictor of ewe wool shedding
}

\author{
Napoleón Vargas Jurado $^{1}$ | Larry A. Kuehn ${ }^{2} \quad$ Ronald M. Lewis ${ }^{1}$ (D)
}

${ }^{1}$ Department of Animal Science, University of Nebraska - Lincoln, Lincoln, Nebraska

${ }^{2}$ Roman L. Hruska U.S. Meat and Animal Research Center, Clay Center, Nebraska

\section{Correspondence}

Ronald M. Lewis, Department of Animal Science, University of Nebraska - Lincoln, Lincoln, NE.

Email: rlewis5@unl.edu

Funding information SENESCYT

\begin{abstract}
Interest in reducing labour costs due to shearing has led to development of breed types that shed their wool naturally. Selection at young ages can facilitate response. Reliability of predictions of adult from lamb wool shedding (WS) is thus key in the design of breeding programmes to increase shedding. Our objectives were to estimate heritabilities and genetic relationships between WS measured once in lambs and repeatedly in ewes and to assess the accuracy of lamb WS EBV to predict ewe WS EBV based on a multi-trait threshold or a repeatability model. Data were 4,971 lamb and 3,335 ewe WS records on a Romanov, White Dorper and Katahdin composite flock. For the multivariate model, WS heritability ranged from $0.47 \pm 0.03$ in lambs to $0.59 \pm 0.04$ at 1 year of age. For the repeatability model, WS in adult ewes was moderately heritable $(0.50 \pm 0.03)$ and repeatable $(0.60 \pm 0.02)$. Genetic correlations were $0.72 \pm 0.04,0.65 \pm 0.05,0.50 \pm 0.09$ and $0.51 \pm 0.09$ between lamb WS and 1st through 4th record, respectively. Given the moderately high heritability and high correlations between WS performance in lambs and ewes, selecting animals early in life would effectively increase WS in crossbred flocks.
\end{abstract}

\section{K E Y W O R D S}

genetic correlation, heritability, repeatability, wool shedding

\section{1 | INTRODUCTION}

Due to the labour cost associated with shearing and considerable variability in wool prices, there has been interest in developing low-input breeds (or breed types) of sheep that do not require shearing yet still express other economically important attributes. Hair breeds that naturally shed (moult) their wool annually have therefore been integrated into crossbred populations (Allain, Pena, Foulquie, Bourdillon, \& François, 2014; Matika, Bishop, Pong-Wong, Riggio, \& Headon, 2013; Vargas Jurado, Leymaster, Kuehn, \& Lewis, 2016). Wool shedding (WS), however, is a relatively novel trait, and the genetic factors affecting the extent of WS are not entirely known (Matika et al., 2013; Pollott, 2011).

Contrary to some traits that are measured once in the life of an individual (e.g., birth, weaning and yearling weight), the ability of an animal to shed its wool can be measured repeatedly throughout its life. This is especially true for ewes retained as breeding animals in a flock. In selection programs with a goal of increased shedding, an important consideration is whether a ewe's WS as an adult can be reliably predicted from a record obtained as a lamb. While it would be reasonable to assume that WS in lambs and adults may be different traits, a high genetic correlation between lamb WS and WS as two-year-olds has been reported in a flock of Easycare sheep (Pollott, 2011). Still, because of the diverse breed make-up of these composite populations, it is important to determine the strength of these genetic relationships in other populations.

Although in some cases WS can be defined as a continuous trait (e.g., the percentage of body area not covered by wool), in practice, the extent to which an animal sheds its wool is usually assessed on an ordinal scale. The number of ordered categories into which WS is classified in the literature is variable and ranges from 5 (Pollott, 2011) to 10 (Matika et al., 
2013). With ordinal scales, normality cannot always be assumed (or guaranteed), and thus, the use of threshold (probit) models is necessary to estimate breeding values and variance components (Sorensen, Andersen, Gianola, \& Korsgaard, 1995; Sorensen \& Gianola, 2002).

In practice, WS may be recorded at various ages (yearly), and thus, multiple EBV may be available for adult WS. When selecting individuals, a single EBV aggregating all information on an animal is often preferable. Several approaches to obtain such an estimate may be used including averaging multiple adult WS EBV or fitting a repeatability model. It is important then to determine if adult WS EBV, regardless of how obtained, are consistently predicted by lamb WS EBV. The objectives of this study were as follows: (a) to estimate heritability of WS in lambs and in ewes at various ages; (b) to determine the genetic relationships between WS measured once in lambs and annually in ewes; and (c) to assess the accuracy of lamb WS EBV to predict ewe WS EBV when fitting either a multi-trait threshold or a repeated measurement (repeatability) model.

\section{2 | MATERIALS AND METHODS}

Data for this study were obtained from a composite maternal line developed at the Roman L. Hruska United States Meat and Animal Research Center (USMARC, Clay Center, Nebraska). Animals were raised in accordance with the Guide for the Care and Use of Agricultural Animals in Agricultural Research and Teaching (Federation of Animal Science Societies, 2010), and their care was approved by the USMARC Animal Care and Use Committees.

\section{1 | Composite population}

A crossbred flock was composed of five lines: 1/2 Katahdin-1/2 Romanov crosses $\left(\mathrm{F}_{1}\right), 1 / 2$ White Dorper-1/2
Romanov crosses $\left(\mathrm{F}_{1}\right.$ and $\left.\mathrm{F}_{2}\right)$ and 1/2 Romanov-1/4 Katahdin-1/4 White Dorper crossbreds $\left(\mathrm{F}_{1}\right.$ and $\left.\mathrm{F}_{2}\right)$. Development of the line started in 2006 and focused mainly on polled individuals with short tails, increased WS, and the ability to rear twin (or triplet) lambs. Ewes with a propensity to shed and that produced and reared larger litters were favoured for breeding. They were lambed on pasture. Lambs were moved to group-feeding pens after weaning. A more detailed description of the composite population can be found in Vargas Jurado et al. (2016).

\subsection{Wool shedding data}

Performance data were collected from 2007 to 2011 and included a single lamb wool shedding (WSL) record on 4,971 animals as well as up to four ewe WS records (WS1, WS2, WS3 and WS4) collected on 1,313 individual animals. Those 1,313 ewes produced a total of 2,851 repeated records. Lambs were on average 170 (SD 12.0) d of age at scoring, while ewes were on average 473 (SD 25.0) d at WS1, 844 (SD 34.6) $\mathrm{d}$ at WS2, 1,215 (SD 33.5) d at WS3, and 1,574 (SD 34.0) d at WS4. The WS1, WS2, WS3 and W4 therefore coincided approximately with ewes that were 1,2, 3 and 4 years old, respectively. WS was assessed using a 9-point scoring system, from 0 to 8 , where 0 and 1 represented animals with less than $25 \%$ of wool coverage, 2 to 6 represented animals between $25 \%$ and $75 \%$ of wool coverage and 7 and 8 represented animals with more than $75 \%$ of wool coverage (Vargas Jurado et al., 2016).

Boxplots and summary statistics including mean, SD and number of observations for each trait are presented on Figure 1.

While lamb records included both male and female WS scores, adult records were available only for ewes. A histogram showing the distribution of WS categories in lambs and adults is presented in Figure 2.

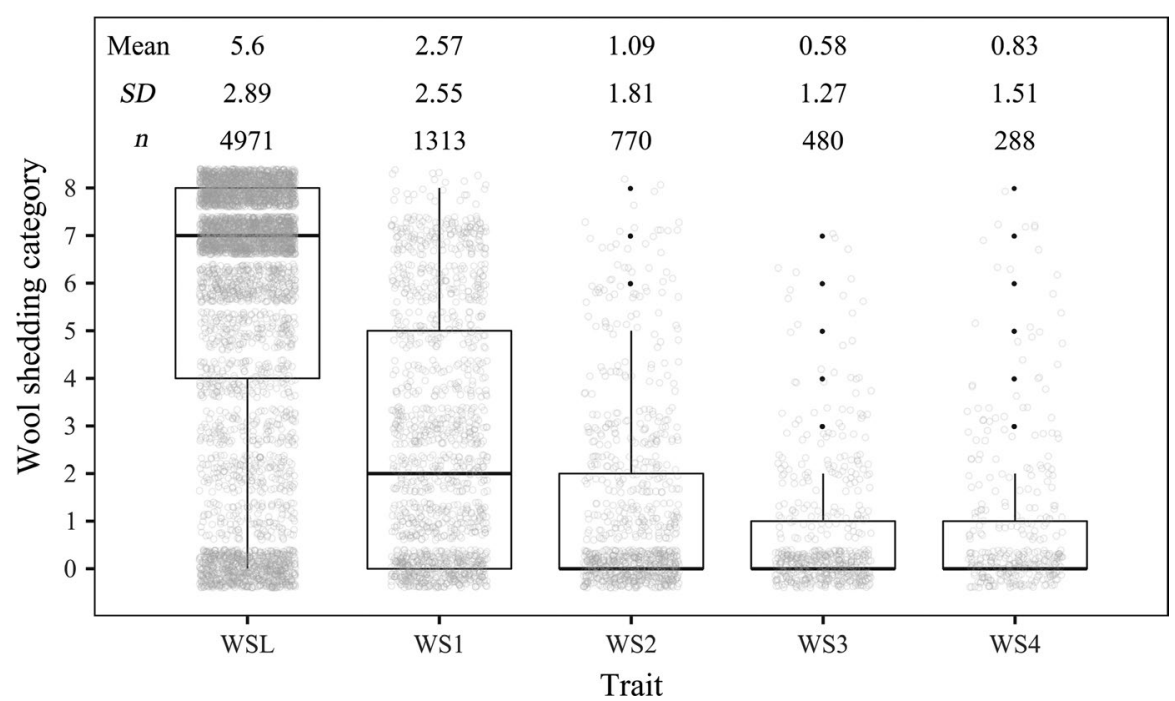

F IG URE 1 Boxplots and summary statistics for lamb wool shedding (WSL, recorded at 170 [SD 12.0] d of age) and 4 ewe wool shedding records (WS1 recorded at 473 [SD 25.0] d of age, WS2 recorded at 844 [SD 34.6] d of age, WS3 recorded at 1,215 [SD 33.5] d of age and WS4 recorded at 1,574 [SD 34.0] d of age). Grey circles show individual records 
With the extremely skewed and unbalanced distribution of the WS data (many observations located at the 0 and 8 categories, respectively), a threshold model was used for their analysis (Sorensen \& Gianola, 2002).

\section{3 | Estimating breeding values and variance components}

\subsection{1 | Multivariate model}

Due to the (ordered) categorical nature of WS scores a multivariate threshold model was fitted (Korsgaard et al., 2003; Sorensen \& Gianola, 2002). Briefly, elements of the response vector $y_{i j}$ took values in one of $K=9$ ordered WS categories, where $j=1, \ldots, 5$ which corresponded to WSL, WS1, WS2, WS3 and WS4, and $i=1, \ldots, n_{j}$ was the index for the observations in the $j$ th trait. The model then took the form.

$$
\begin{gathered}
P\left(y_{i j}=k \mid \boldsymbol{\beta}_{j}, \mathbf{a}_{j}, \boldsymbol{\tau}_{j}, \sigma_{e_{j}}^{2}\right)=\boldsymbol{\Phi}\left(\frac{\tau_{j k}-\eta_{i j}}{\sigma_{e_{j}}}\right)-\boldsymbol{\Phi}\left(\frac{\tau_{j(k-1)}-\eta_{i j}}{\sigma_{e_{j}}}\right),{ }_{(1)} \\
\eta_{i j}=\mathbf{x}_{i j}^{\mathrm{T}} \boldsymbol{\beta}_{j}+\mathbf{z}_{i j}^{\mathrm{T}} \mathbf{a}_{j}
\end{gathered}
$$

where $k=1, \ldots, K$ denoted the index of categories, $\boldsymbol{\Phi}(\cdot)$ denoted the standard Normal cumulative distribution function, $\eta_{i j}$ was the linear predictor for the $i$ th observation in the $j$ th trait and $\boldsymbol{\beta}_{j}$ and $\mathbf{a}_{j}$ represented the vectors of fixed and random (animal) effects for the $j$ th trait, respectively. In addition, $\mathbf{x}_{i j}$ and $\mathbf{z}_{i j}$ were incidence vectors associated with the fixed and random effects, respectively. Finally, $\sigma_{e_{j}}^{2}$ was the residual variance for the $j$ th trait, and $\boldsymbol{\tau}_{j}$ was the vector of unknown threshold (or cutpoint) parameters for the $j$ th trait.
By introducing a latent variable $u_{i j}$ model (1) could be expressed as:

$$
\begin{aligned}
& P\left(y_{i j}=k \mid u_{i j}, \boldsymbol{\tau}\right) \propto \sum_{k=1}^{K} \mathrm{II}\left(\tau_{j(k-1)}<u_{i j} \leq \tau_{j k}\right) \mathrm{II}\left(y_{i j}=k\right), \\
& u_{i j} \mid \boldsymbol{\beta}_{j}, \mathbf{a}_{j}, \sigma_{e_{j}}^{2} \quad \sim \operatorname{Normal}\left(\mathbf{x}_{i j}^{\mathrm{T}} \boldsymbol{\beta}_{j}+\mathbf{z}_{i j}^{\mathrm{T}} \mathbf{a}_{j}, \sigma_{e_{j}}^{2}\right),
\end{aligned}
$$

where II (.) was an indicator function (Sorensen \& Gianola, 2002).

For WSL the fixed effects were sex, age of dam (six levels), and born and reared category. The birth and rearing categories were defined as 1 if a lamb was born as a single and raised as a single, 2 if a lamb was born as a twin but raised as a single, 3 if a lamb was born as a triplet but raised as a single, 4 if a lamb was born and raised as a twin, 5 if a lamb was born as a triplet but raised as a twin and 6 if a lamb was born and raised as a triplet. Finally, contemporary group was defined as the combination of genetic line by year (15 levels). Every genetic line did not occur in all years. For adult WS traits, fixed effects were born and rearing category (in the ewe's parity) and contemporary group. Model validation (significance of effects) was done by fitting a cumulative link mixed model using the ordinal package (Christensen, 2018) and performing an analysis of deviance using the RVAideMemoire package (Hervé, 2018) in R (R Core Team, 2018).

Lastly, it was assumed that random (animal) effects were normally distributed with mean zero and variance given by:

$$
\operatorname{Var}\left(\left[\begin{array}{c}
\mathbf{a}_{W S L} \\
\vdots \\
\mathbf{a}_{W S 4}
\end{array}\right]\right)=\mathbf{G} \otimes \mathbf{A}
$$

FIG URE 2 Distribution of wool shedding categories for one lamb wool shedding record (WSL, recorded at $170[S D$ 12.0] $\mathrm{d}$ of age) and 4 ewe wool shedding records (WS1 recorded at 473 [SD 25.0] d of age, WS2 recorded at 844 [SD 34.6] d of age, WS3 recorded at 1,215 [SD 33.5] d of age and WS4 recorded at 1,574 [SD 34.0] d of age)

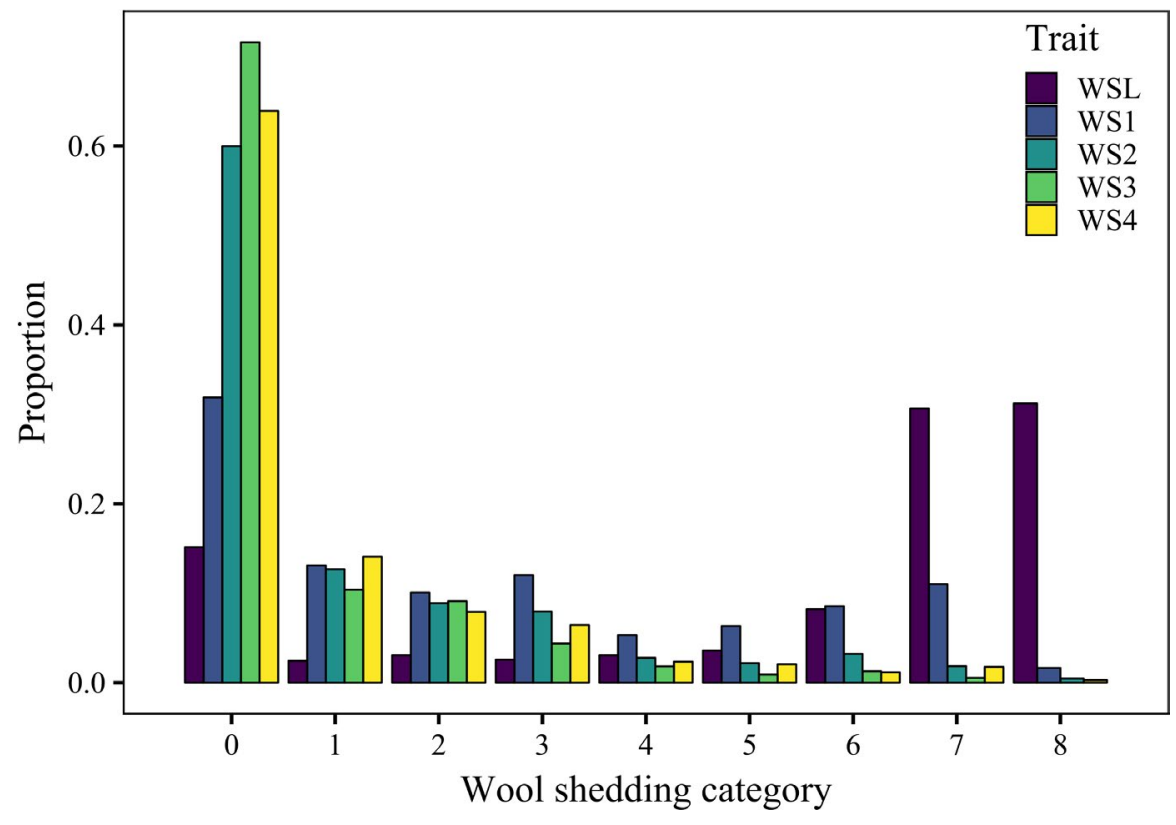




$$
\mathbf{G}=\left[\begin{array}{cccc}
\sigma_{a_{W S L}}^{2} & \sigma_{a_{W S L, W S 1}} & \cdots & \sigma_{a_{W S L, W S 4}} \\
& \sigma_{a_{W S 1}}^{2} & \cdots & \sigma_{a_{W S 1, W S 4}} \\
& S y m . & \ddots & \vdots \\
& & & \sigma_{a_{W S 4}}^{2}
\end{array}\right],
$$

where $\mathbf{G}$ was the additive genetic (co)variance matrix among traits, $\sigma_{a_{W S L}}^{2}, \sigma_{a_{W S 1}}^{2}, \ldots, \sigma_{a_{W S 4}}^{2}$ were the additive genetic variances for the lamb and four adult traits, respectively, and $\sigma_{a_{W S L W S 1}}, \ldots, \sigma_{a_{W S 3, W S 4}}$ were the additive genetic covariances among lamb and adult traits. In addition, $\mathbf{A}$ was the numerator relationship matrix, and lastly, $\mathbf{a}_{W S L}, \mathbf{a}_{W S 1}, \ldots, \mathbf{a}_{W S 4}$ represented the additive genetic effects for the lamb trait $\left(\mathbf{a}_{W S L}\right)$ and four adult traits $\left(\mathbf{a}_{W S 1}, \ldots, \mathbf{a}_{W S 4}\right)$, respectively.

\subsection{2 | Bivariate repeatability model}

A drawback of the multivariate model where adult measurements at different ages are considered separate but correlated traits is that substantially more (co)variance parameters need to be estimated. An alternative could be to consider all adult traits as repeated measurements of the same (adult) trait. The lamb and a single repeatedly measured adult trait therefore also were analysed using a bivariate threshold model. The linear predictor for WSL was similar to that in (2). Since adult WS was repeatedly measured it also included a vector of permanent environmental effects (pe) so that the linear predictor for the $i$ th observation became $\eta_{i}=\mathbf{x}_{i}^{\mathrm{T}} \boldsymbol{\beta}+\mathbf{z}_{i}^{\mathrm{T}} \mathbf{a}+\mathbf{w}_{i}^{\mathrm{T}} \mathbf{p e}$, where $\mathbf{w}_{i}$ was an incidence vector associated with the permanent environmental effect. Fixed effects for the repeatability model were the same as in the multivariate model but also included the ewe's own age (in years). It was further assumed that:

$$
\begin{gathered}
\operatorname{Var}\left(\left[\begin{array}{c}
\mathbf{a}_{W S L} \\
\mathbf{a}_{W S A} \\
\mathbf{p e}
\end{array}\right]\right)=\left[\begin{array}{cc}
\mathbf{G} \otimes \mathbf{A} & 0 \\
0 & \mathbf{I} \sigma_{P E}^{2}
\end{array}\right], \\
\mathbf{G}=\left[\begin{array}{cc}
\sigma_{a_{W S L}}^{2} & \sigma_{a_{W S L, W S A}} \\
\sigma_{a_{W S A, W S L}} & \sigma_{a_{W S A}}^{2}
\end{array}\right] .
\end{gathered}
$$

where $\mathbf{a}_{W S L}$ and $\mathbf{a}_{W S A}$ denoted the lamb and adult animal (additive genetic) effects, respectively. Finally, the $\mathbf{G}$ matrix contained the genetic variances $\left(\sigma_{a_{L}}^{2}, \sigma_{a_{A}}^{2}\right)$ and covariance $\left(\sigma_{a_{W S A, W S L}}\right.$ ) between lamb and adult WS, and $\sigma_{P E}^{2}$ was the permanent environmental variance.

All models (multivariate and repeatability) were fitted using DMU (Madsen, Jensen, Labouriau, Christensen, \& Sahana, 2014). A single chain of 55,000 iterations was run with the first 5,000 iterations discarded (burn-in samples) and a thinning interval of five, for a total of 10,000 samples for posterior inference. Convergence was examined using traceplots, and the Raftery-Lewis and Geweke diagnostics using the coda (Plummer, Best, Cowles, \& Vines, 2006) package in $\mathrm{R}$.

\section{4 | Predicting adult performance based on lamb records}

Of particular interest in this study was assessing whether lamb WS performance could reliably predict adult WS performance. However, when considering adult (ewe) WS records as separate but correlated traits, there were up to four observations available on an individual ewe. Since in practice a single EBV for adult WS typically would be desired, adult WS EBV were averaged (AEBV). On the other hand, a single adult WS EBV was obtained when fitting the repeatability model (REBV), which simplified matters. An alternative approach might be to predict WS EBV at approximately 1 year of age (EBV1, 473 (SD 25.0) d of age) as a proxy for adult shedding based on lamb WS EBV; the efficacy of such a prediction therefore also was considered.

To determine which of these methods may be more accurate, animals were ranked based on their lamb EBV and also (separately) based on their AEBV, REBV and EBV1. The proportion of individuals located in the bottom 5\%, 10\%, 20\%, $30 \%, 40 \%$ and $50 \%$ for both the lamb WS EBV and an adult EBV (defined as AEBV, REBV or EBV1) was calculated. The reason for choosing the bottom $j$ th $\%$ (instead of the top) was because lower WS scores were associated with increased shedding and thus desirable. Those animals common to both the lamb and a given adult WS EBV (based on multivariate, repeatability or yearling analysis) were defined as three sets for each of the proportions selected. The intersection of individuals between each pair of these sets was then calculated for each proportion as a further comparison. The regression of adult WS EBV on lamb WS EBV also was calculated. Furthermore, Spearman's rank correlation and Kendall's $\tau$ were calculated between lamb WS EBV and adult WS EBV.

\section{RESULTS AND DISCUSSION}

Sex, rearing type (number born and reared), age of dam and contemporary group all affected WS $(P<0.001, P<0.001$, $P=0.002$, and $P=0.012$, respectively). Ewe lambs tended to shed more (mean WS score $5.35 \pm 0.08$ ) than ram lambs (mean WS score 5.72 \pm 0.08 ). In other crossbred populations, sex only appeared to have a slight effect on WS (Pollott, 2011). However, O'Connell, Scobie, Hickey, Sumner, and Pearson (2012) reported an effect of sex and selection line (similar to contemporary group in our study) on fleece shedding in 
TABLE 1 Mean wool shedding (WS) (estimated marginal means) and SE for genetic line in the crossbred flock

\begin{tabular}{lll} 
Line & Mean WS & SE \\
\hline $\mathrm{F}_{1} 1 / 2$ Katahdin 1/2 Romanov & 4.81 & 0.33 \\
$\mathrm{~F}_{1} 1 / 2$ White Dorper 1/2 Romanov & 6.50 & 0.29 \\
$\mathrm{~F}_{2} 1 / 2$ White Dorper 1/2 Romanov & 5.14 & 0.20 \\
$\mathrm{~F}_{1} 1 / 4$ White Dorper 1/2 Romanov 1/4Katahdin & 5.38 & 0.18 \\
$\mathrm{~F}_{2} 1 / 4$ White Dorper 1/2 Romanov 1/4 Katahdin & 4.66 & 0.18 \\
\hline
\end{tabular}

yearling Wiltshire Horn sheep, which was not observed in lamb fleece shedding. The number of lambs born and reared also had an effect on WS $(P<0.001)$ while age did not $(P=0.99)$, which may be due to the variability in WS (Figure 1 ). Ewes not rearing lambs shed less (mean WS $2.61 \pm 0.19$ ) than those ewes carrying two lambs but that reared a single lamb (mean WS $2.28 \pm 0.11$ ) or that carried and reared a single lamb (mean WS $2.32 \pm 0.09$ ). There were no differences $(P>0.32)$ with contrasts among the other birth-rearing categories. This was likely due to the lower number of ewes that produced and reared larger litters, resulting in less reliable estimates. For the repeatedly measured adult trait, contemporary group did have an effect on WS $(p<.001)$.

Lines differed in their extent of WS (Table 1). Most importantly the $\mathrm{F}_{2} 1 / 4$ White Dorper $1 / 4$ Katahdin and 1/2 Romanov shed the most (mean WS $4.66 \pm 0.18$ ), which perhaps reflected changes due to phenotypic selection, while the $F_{1} 1 / 2$ White Dorper 1/2 Romanov shed the least (mean WS $6.50 \pm 0.29$ ). With the Katahdin and White Dorper foundation to the crossbred flock, it was presumed most animals would express a propensity to shed, as these breeds are hypothesized to carry a dominant shedding allele (Pollott, 2011). The presence of a dominant allele was not tested in this flock. Even though some animals within each line failed to shed, their performance would still be consistent with a dominant mode of inheritance.

For WSL approximately 0.18 of the observations corresponded to WS scores of 0 and 1 , while 0.62 corresponded to WS of 7 or 8 . On the other hand, the proportion of ewes with WS scores of 0 and 1 increased to 0.45 , and the proportion of ewes with WS scores of 7 and 8 decreased to 0.13. In the Romane breed (Allain, Pena, Foulquié, Bourdillon, \& François, 2011), mean fleece shedding rate was 0.17 (implying that on average around $17 \%$ of the body was not covered by wool), and approximately 0.42 of adult ewes shed their fleece partially. The same tendency was observed as age increased, and thus, overall mean WS decreased from a mean of 5.60 in lambs to a mean of 0.58 at 3 years of age (Figure 1). A similar trend was observed in the Romane breed (Allain et al., 2014) where both the ability of shedding (defined as the percentage of animals that partly shed their fleece) and the extent of shedding (defined as the ratio of shed area to total body area) increased from $42.7 \%$ and $6.0 \%$, respectively, in lambs to $52.4 \%$ and
$17.2 \%$, respectively, at 3 years of age. A slight decrease was observed in both ability and extent of shedding at 4 years of age. This decrease in WS at higher ages in our, and perhaps the Allain et al. (2014), study may reflect the smaller number of records available at this age. Pollott (2011) also reported a small increase in WS with age in Easycare sheep, from a mean of 2.6 in lambs to 3.5 at 3 years of age and older; in Pollott (2011), the higher scores were associated with increased shedding.

\section{1 | Variance component estimation}

\subsection{1 | Multivariate model}

In general, estimates of heritability for WS were relatively consistent across ages, ranging from $0.47 \pm 0.03$ for WS in lambs to $0.59 \pm 0.04$ for WS at 1 year of age (Table 2). Pollott (2011) reported a heritability of shedding scores of $0.45 \pm 0.11$ and $0.26 \pm 0.06$ in Easycare lambs and older animals, respectively. Similarly, although higher than those reported by Pollott (2011), WS heritability was $0.73 \pm 0.11$ in Romane ewe lambs and $0.69 \pm 0.05$ in Romane adults (Allain et al., 2014). It is important to note that Allain et al. (2014) used a threshold model, while Pollott (2011) assumed a linear mixed model (Gaussian). Similar estimates of WS heritability were also reported by Matika et al. (2013) ranging from $0.65 \pm 0.08$ , when WS was considered a binary trait, to $0.80 \pm 0.08$, when considered a continuous trait. It appears that regardless of the genetic make-up of the (crossbred) population, a substantial fraction of WS variability can be exploited for genetic selection and improvement.

Genetic correlations among traits ranged from $0.42 \pm 0.10$ between WS at 3 and 4 years of age to $0.72 \pm 0.04$ between WSL and at 1 year of age (Table 2). On the other hand, Pollott (2011) and Allain et al. (2014) reported higher genetic correlations of $0.86 \pm 0.09$ and $0.94 \pm 0.08$, respectively, between WS in lambs and older animals. Still, such relationship among traits would imply that WS in lambs is a reasonably good predictor of WS at 1 year of age.

\subsection{2 | Bivariate repeatability model}

Variance components from the repeatability model are provided in Table 3. As mentioned earlier, using a repeatability 


\begin{tabular}{|c|c|c|c|c|c|}
\hline \multirow{2}{*}{$\begin{array}{l}\text { Additive } \\
\text { genetic } \\
\text { variance }\end{array}$} & \multicolumn{5}{|l|}{ Trait $^{\mathrm{a}}$} \\
\hline & Lamb & 1st adult & 2nd adult & 3rd adult & 4th adult \\
\hline & $0.197(0.018)$ & $0.082(0.009)$ & $0.061(0.008)$ & $0.074(0.012)$ & $\begin{array}{l}0.062 \\
(0.012)\end{array}$ \\
\hline Lamb & $0.47(0.034)$ & & & & \\
\hline 1 st adult & $0.72(0.038)$ & $0.59(0.042)$ & & & \\
\hline 2nd adult & $0.65(0.050)$ & $0.68(0.048)$ & $0.53(0.049)$ & & \\
\hline 3rd adult & $0.50(0.087)$ & $0.56(0.076)$ & $0.49(0.082)$ & $0.48(0.058)$ & \\
\hline 4th adult & $0.51(0.091)$ & $0.52(0.090)$ & $0.50(0.091)$ & $0.42(0.101)$ & $0.51(0.067)$ \\
\hline
\end{tabular}

${ }^{\mathrm{a}} \mathrm{Lamb}$ wool shedding recorded at $170(S D 12.0) \mathrm{d}$ of age; 1 st adult wool shedding trait recorded at 473 (SD 25.0) d of age; 2nd adult wool shedding trait recorded at 844 (SD 34.6) d of age; 3rd adult wool shedding trait recorded at 1,215 ( $S D$ 33.5) d of age; and 4th wool shedding trait recorded at 1,574 (SD 34.0) d of age.
T A B L E 2 Estimates (posterior means) of additive genetic variance, heritability (diagonal) and genetic correlation (below diagonal) for lamb and four adult wool shedding measurements. Posterior $S D$ in parenthesis
TA BLE 3 Posterior mean and $S D$ for estimates of variance, heritability, genetic correlations between lamb and adult wool shedding scores, and repeatability of adult wool scores

\begin{tabular}{|c|c|c|}
\hline Parameter $^{\mathrm{a}}$ & Mean & $S D$ \\
\hline$\sigma_{a_{L}}^{2}$ & 0.218 & 0.019 \\
\hline$\sigma_{a_{A}}^{2}$ & 0.053 & 0.005 \\
\hline$\sigma_{a_{A, L}}$ & 0.079 & 0.007 \\
\hline$\sigma_{P E}^{2}$ & 0.024 & 0.002 \\
\hline$h_{L}^{2}$ & 0.505 & 0.032 \\
\hline$h_{A}^{2}$ & 0.501 & 0.026 \\
\hline$r_{A}^{2}$ & 0.602 & 0.017 \\
\hline$\rho_{A, L}$ & 0.766 & 0.031 \\
\hline \multicolumn{3}{|c|}{$\begin{array}{l}\mathrm{a} \sigma_{a_{L}}^{2} \text { was lamb wool shedding additive genetic variance, } \sigma_{a_{A}}^{2} \text { was adult wool } \\
\text { shedding additive genetic variance, } \sigma_{a_{A, L}} \text { denotes lamb and adult wool shedding } \\
\text { additive genetic covariance, } \sigma_{P E}^{2} \text { was the permanent environmental variance, } h_{L}^{2} \\
\text { was lamb wool shedding heritability, } h_{A}^{2} \text { was adult wool shedding heritability, } r_{A}^{2} \\
\text { was the repeatability of adult wool shedding and } \rho_{A, L} \text { was the genetic correlation } \\
\text { between lamb and adult wool shedding. }\end{array}$} \\
\hline
\end{tabular}

model has the advantage of resulting in considerably fewer parameters to be estimated. Here, it amounts to estimating the values of four (co)variances, resulting in two heritabilities and a repeatability; in the multivariate model, there were 15 (co)variances to estimate with five heritabilities.

Heritability estimates were $0.51 \pm 0.03$ for lambs and $0.50 \pm 0.03$ for and adult WS score. Consistent estimates of WS heritability therefore can be obtained regardless of the model used. The genetic correlation between lamb and ewe WS was similar, although slightly higher, in the repeatability model $(0.77 \pm 0.03)$ as compared to the genetic correlation between lamb WS and WS at one year of age in the multivariate model $(0.72 \pm 0.04)$. Again, there appears to be consistency among estimates of genetic correlations irrespective of the model used.

The repeatability of WS was $0.60 \pm 0.02$, which was lower than the value of $0.77 \pm 0.01$ reported by O'Connell et al. (2012) in a New Zealand Wiltshire Horn sheep flock. Permanent environmental effect therefore appears to play a
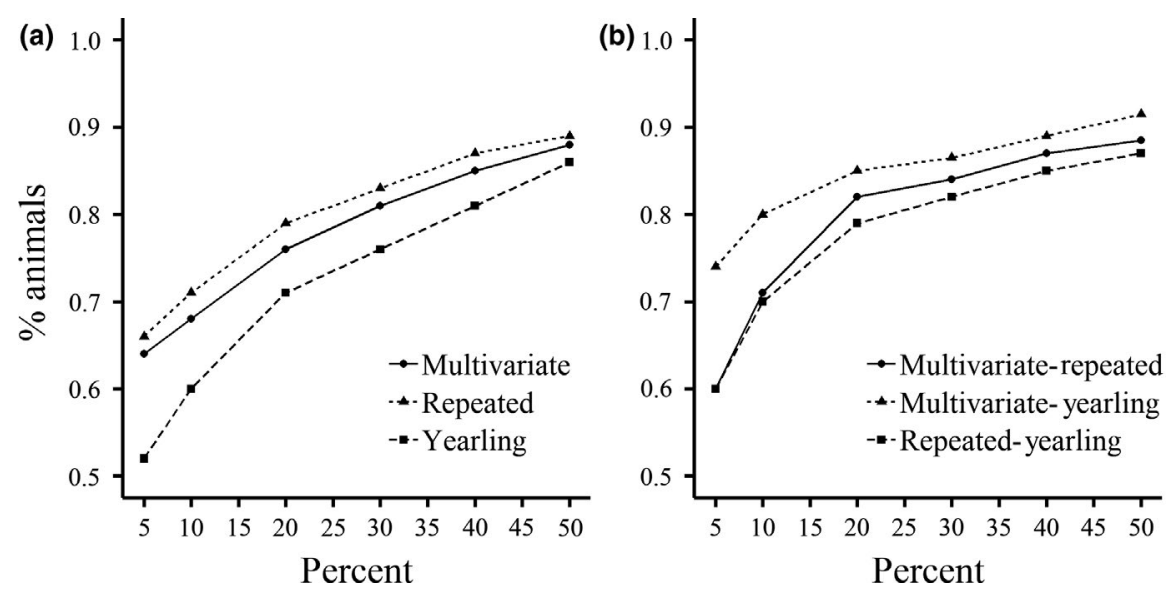

F I G URE 3 Proportion of animals (a) in the bottom 5\%, 10\%, 20\%, 30\%, 40\% and 50\% of both lamb and ewe WS EBV defined as (i) the average EBV of four adult WS EBV from a multivariate model, (ii) yearling WS EBV or (iii) repeatability model WS EBV; (b) in the bottom 5\%, $10 \%, 20 \%, 30 \%, 40 \%$ and $50 \%$ selected by one pair of methods (e.g., lamb and multivariate model WS EBV) that would also be selected by a pair of the remaining methods (e.g., lamb and yearling WS EBV) 
small role, accounting for approximately a 10 per cent of the variation in WS. Still, the substantial repeatability of the trait suggests that selection based on one or two measures would be effective.

\section{2 | Predicting adult performance based on lamb performance}

The proportion of animals in the bottom $j$ th $\%$ in both lamb and adult WS EBV was moderately high and ranged from 0.53 for EBV1 (yearling) for the bottom 5\% to 0.90 for REBV (repeated) for the bottom 50\% (Figure 3a). If animals were to be selected at the highest intensity (bottom 5\%) approximately $63 \%$ (or $66 \%$ ) of the same animals would be in the selected set for the multivariate (or repeatability) model.

T A B L E 4 Estimates of Spearman's rank correlation and Kendall's $\tau$ between lamb and adult wool shedding (WS) EBV

\begin{tabular}{|llll} 
Adult WS EBV & Method & Estimate & C.I. $^{\text {b }}$ \\
\hline Multivariate & Spearman & 0.916 & $(0.912,0.920)$ \\
& Kendall & 0.751 & $(0.746,0.757)$ \\
\hline \multirow{2}{*}{ Repeatability } & Spearman & 0.929 & $(0.926,0.934)$ \\
& Kendall & 0.776 & $(0.771,0.781)$ \\
\hline Yearling & Spearman & 0.881 & $(0.876,0.886)$ \\
& Kendall & 0.704 & $(0.697,0.711)$ \\
\hline
\end{tabular}

${ }^{a}$ Average EBV: average wool shedding EBV derived from a multivariate threshold model where ewe wool shedding EBV were considered separate but correlated traits; repeatability EBV: ewe wool shedding EBV obtained from a repeatability model; yearling EBV: wool shedding EBV at 1 year of age. ${ }^{\mathrm{b}}$ Asymptotic confidence interval obtained as in Bonnett and Wright (2000).
There was a moderately high agreement in the proportion of animals selected by one set of methods as in another set of methods (Figure 3b), which increased with the percentage of animals retained. Also, Spearman's rank correlation and Kendall's $\tau$ correlation coefficients between lamb and ewe WS EBV were high (Table 4).

From Table 4, the repeatability model provided the most accurate prediction of adult WS EBV based on lamb performance with the Spearman correlation coefficient of $0.93 \pm 0.003$ and a Kendall's $\tau$ correlation of $0.78 \pm 0.01$; the respective values for the multivariate analyses were $0.92 \pm 0.004$ and $0.75 \pm 0.01$ . Clearly, both approaches provided accurate and similar predictions. Still, the confidence intervals of these correlation estimates did not overlap. Also, based on the regression of adult on lamb WS EBV, the repeatability model provided a slightly better fit (larger $R^{2}$; Figure 4).

While results from genetic multivariate analyses (beyond lamb and yearlings) have not been presented previously in the literature (to the best of our knowledge), Pollott (2011) reported a phenotypic correlation between WS measured in lambs and as older animals of $0.51 \pm 0.04$, which decreased between shedding scores at successive older ages. O'Connell et al. (2012) reported a phenotypic correlation of $0.78 \pm 0.01$ between WS scored in December and January. The genetic correlation of WS between those two events was $0.99 \pm 0.01$ , which seems reasonable given that these shedding events were within a month time span. The genetic relationships between WS at different ages in our study were strong $(>0.42)$, particularly when shedding events were separated by one year. This again substantiates that WS performance in lambs is a good indicator of performance in ewes.
F I G U R E 4 Linear regression of adult on lamb wool shedding EBV. Adult wool shedding was obtained as (a) averaged ewe EBV obtained by fitting a multivariate (four adult traits) model, (b) ewe EBV yearling (recorded at 473 (SD 25.0) d of age) or (c) ewe EBV obtained from a repeatability model of four adult WS records

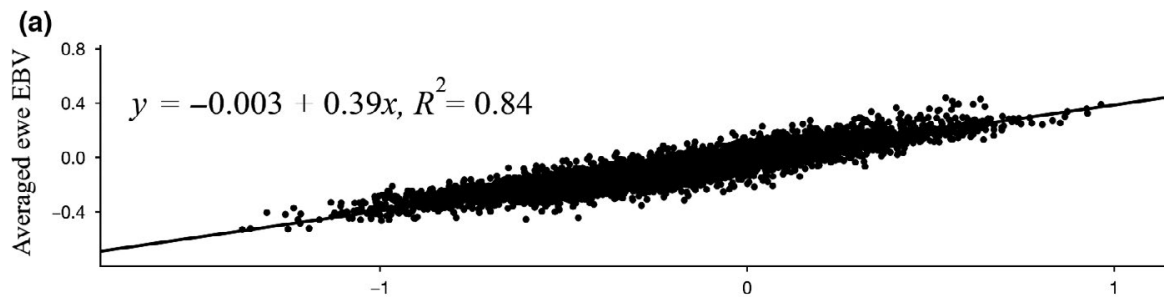

(b)

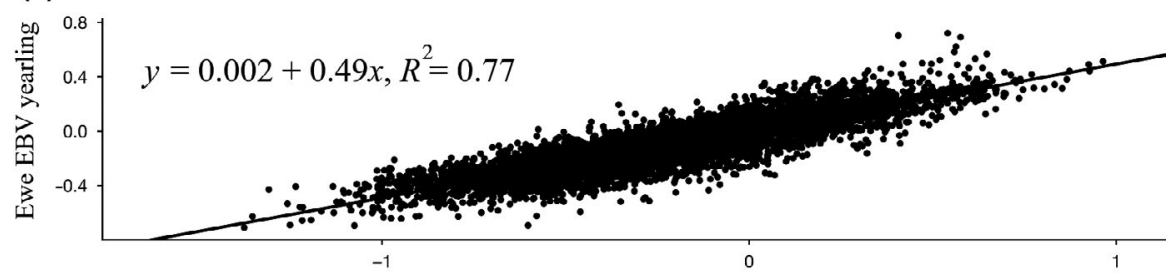

(c)

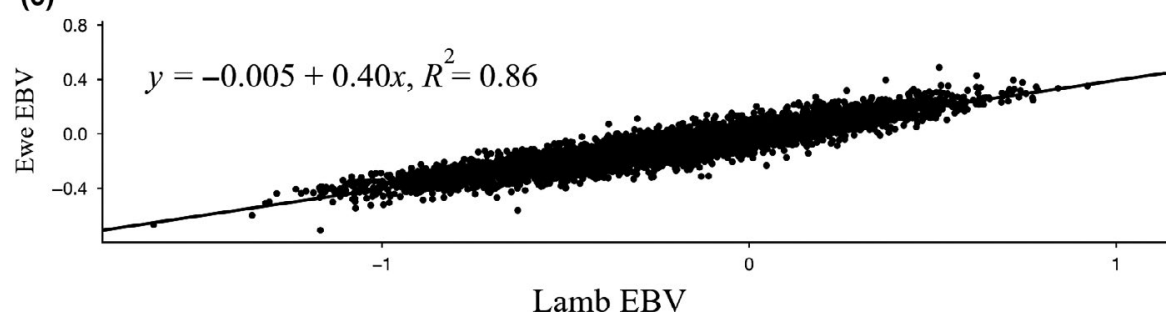


From the analyses performed, it appears that the repeatability methodology provides a model that better described the relationship between WS in lambs and WS in ewes at successive (older) ages. When fitting a repeatability model, it was assumed that the same trait was measured repeatedly. However, from Table 2, the correlations between successive measurements of WS ranged from $0.42( \pm 0.10)$ to $0.72( \pm 0.04)$, thereby differing from unity that suggests WS measured at different ages may be different traits. Although such may be the case, with the aim of obtaining an adult WS EBV, the repeatability model provided the most reliable predictions and was computationally simpler. Furthermore, the categorical (ordinal) nature of WS, as well as less records being available for the estimation of (co)variances at older ages, may have contributed to lower estimates of genetic and phenotypic correlations.

\section{CONCLUSION}

WS appears to be moderately heritable regardless of whether successive WS events are characterized as separate (but correlated) traits or repeated measurements of the same trait. When a repeatability model was used, WS was found to be moderately repeatable. When considered as separate traits, the genetic correlations between WS at different ages were moderately high. Correlations between lamb WS EBV and adult WS EBV, defined as AEBV EBV1 or REBV, also were moderately high, suggesting that culling or keeping animals based on lamb performance would be an effective way to increase the proportion of shedding in the flock. Because of the moderately high heritability of the trait and the considerable phenotypic variation in WS, a substantial increase in WS could be achieved in a relatively short amount of time. Finally, given that using a repeatability model resulted in greater accuracy of prediction of adult WS, and with less parameters to be estimated (reducing uncertainty), it is likely the preferred approach for analysing WS measured in adult ewes.

\section{ACKNOWLEDGEMENTS}

The USDA is an equal opportunity provider and employer. The mention of trade names or commercial products in this article is solely for the purpose of providing specific information and does not imply recommendation or endorsement by the USDA. The authors wish to thank Kreg A. Leymaster and the technical staff at the Roman L. Hruska U.S. Meat Animal Research Center (Clay Center, NE, USA) for their support of the experimental programme. In addition, financial support of the Ph.D. programme of Napoleón Vargas Jurado from SENESCYT in Ecuador is greatly appreciated.

\section{CONFLICT OF INTEREST}

The authors declare they have no conflict of interest.

\section{DATA AVAILABILITY STATEMENT}

The data that support the findings of this study are available from the corresponding author upon reasonable request.

\section{ORCID}

Ronald M. Lewis (iD https://orcid. org/0000-0002-1658-443X

\section{REFERENCES}

Allain, D., Pena, B., Foulquié, D., Bourdillon, Y., \& François, D. (2011). Genetic variability of fleece shedding in the Martinik hair, Romane sheep breeds and their crossbreds. In Fibre production in South American camelids and other fibre animals (pp. 15-24). Wageningen: Wageningen Academic Publishers.

Allain, D., Pena, B., Foulquie, D., Bourdillon, Y., \& François, D. (2014). Introgression of wool-shedding genes into the Romane breed sheep. In Proceedings of the 10th World Congress on Genetics Applied to Livestock Production, Vancouver, Canada.

Bonnett, D. G., \& Wright, T. A. (2000). Sample size requirements for estimating Pearson, Spearman and Kendall correlations. Psychometrika, 65, 23-28.

Christensen, R. H. B. (2018). Cumulative Link Models for ordinal regression with the R package ordinal. Journal of Statistical Software, Submitted. https://cran.rproject.org/web/packages/ordinal/vignettes/ clm_article.pdf

Federation of Animal Science Societies. (2010). Guide for the care and use of agricultural animals in research and teaching. Champaign, IL: Author.

Hervé, M. (2018). RVAideMemoire: Testing and plotting procedures for Biostatistics. R package version 0.9-69-3. Retrieved from https:// CRAN.R-project.org/package $=$ RVAideMemoire

Korsgaard, I. R., Lund, M. S., Sorensen, D., Gianola, D., Madsen, P., \& Jensen, J. (2003). Multivariate Bayesian analysis of Gaussian, right censored Gaussian, ordered categorical and binary traits using Gibbs sampling. Genetics Selection Evolution, 35, 159-183. https:// doi.org/10.1186/1297-9686-35-2-159

Madsen, P., Jensen, J., Labouriau, R., Christensen, O. F., \& Sahana, G. (2014). DMU-a package for analyzing multivariate mixed models in quantitative genetics and genomics. In Proceedings of the 10th World Congress of Genetics Applied to Livestock Production, Vancouver, Canada.

Matika, O., Bishop, S. C., Pong-Wong, R., Riggio, V., \& Headon, D. J. (2013). Genetic factors controlling wool shedding in a composite Easycare sheep flock. Animal Genetics, 44, 742-749. https://doi. org/10.1111/age. 12070

O'Connell, D., Scobie, D. R., Hickey, S. M., Sumner, R. M. W., \& Pearson, A. J. (2012). Selection for yearling fleece weight and its effect on fleece shedding in New Zealand Wiltshire sheep. Animal Production Science, 52, 456-462. https://doi.org/10.1071/ AN11281 
Plummer, M., Best, N., Cowles, K., \& Vines, K. (2006). CODA: convergence diagnosis and output analysis for MCMC. R News, 6, 7-11.

Pollott, G. E. (2011). A suggested mode of inheritance for wool shedding in sheep. Journal of Animal Science, 89, 2316-2325.

R Core Team. (2018). R: A language and environment for statistical computing. $R$ Foundation for Statistical Computing. Vienna, Austria: Author.

Sorensen, D. A., Andersen, S., Gianola, D., \& Korsgaard, I. (1995). Bayesian inference in threshold models using Gibbs sampling. Genetics Selection Evolution, 27, 229-249. https://doi. org/10.1186/1297-9686-27-3-229

Sorensen, D. A., \& Gianola, D. (2002). Likelihood, Bayesian, and MCMC methods in quantitative genetics. New York, NY: Springer Science \& Business Media.
Vargas Jurado, N., Leymaster, K. A., Kuehn, L. A., \& Lewis, R. M. (2016). Estimating heritability of wool shedding in a cross-bred ewe population. Journal of Animal Breeding and Genetics, 133, 396403. https://doi.org/10.1111/jbg.12215

How to cite this article: Vargas Jurado N, Kuehn LA, Lewis RM. Lamb wool shedding is a good predictor of ewe wool shedding. J Anim Breed Genet.

2020;137:365-373. https://doi.org/10.1111/jbg.12449 